\title{
El lenguaje afectivo durante la crisis sanitaria de la gripe $\mathrm{A}^{1}$
}

\section{Affective language during the H1N1 influenza health crisis}

\author{
Ricard Morant Marco \\ y Arantxa Martín López \\ Departamento de Teoría de los Lenguajes \\ y Ciencias de la Comunicación \\ Universitat de València
}

\section{RESUMEN}

El presente artículo analiza los efectos que según la prensa escrita tuvo la llegada de la gripe A en ciertos comportamientos afectivos de la población. Las autoridades sanitarias, tras la expansión del virus H1N1, recomendaron aumentar la distancia social y aconsejaron, entre otras medidas, evitar los besos. Esta manifestación afectiva, en un primer momento, notó los efectos de la pandemia, sobre todo en ciertas actividades y rituales. Sin embargo, una vez pasado el impacto mediático de la gripe A, recuperó su uso y frecuencia habitual, demostrando que las costumbres fuertemente enraizadas se resisten a cambiar.

Palabras clave: Gripe A, Saludo, Beso, Tradiciones populares, Medios de comunicación.

\section{SUMMARY}

In this article we analyze the effects that, as seen through the written press, the arrival of H1N1 had on certain affective behaviors in society. After the spread of H1N1, health authorities recommended maintaining physical distance in social settings and, among other measures, advised against kissing. At first, this show of affection became a victim of the pandemic, especially in certain activities and rituals. However, once the media impact of swine flu had subsided, kissing recovered its habitual place and frequency, demonstrating that customs which are socially and culturally entrenched are resistant to change.

Key words: Swine Flu, Greetings, Kisses, Popular Traditions, Mass Media.

${ }^{1}$ Este artículo se ha realizado en el marco del proyecto I+D titulado "Retórica y cultura en la información periodística sobre salud" (HUM2007-65132), cofinanciado por el Ministerio de Ciencia e Innovación (España) y los fondos FEDER, así como en el proyecto "Verificación experimental de la conciencia del habla examinada mediante pruebas realizadas a hispanohablantes" (FFI 2008-05248). 


\section{INTRODUCCIÓN}

El presente artículo tiene como objetivo analizar la repercusión, que según la prensa, tuvo la gripe $\mathrm{A}^{2}$ en el lenguaje afectivo, especialmente en ciertos besos en contextos profesionales y tradicionales. Las razones por las que se ha elegido este tema son dos. Primero, el interés que despertó este asunto en la opinión pública desde que en 2009 comenzó a hablarse del virus H1N1 y se aconsejó una mayor distancia de interacción entre los ciudadanos. En segundo lugar, porque fue un asunto controvertido con diferentes posturas, desde la de los impulsores de seguir con las fórmulas de salutación de toda la vida (apretones de mano y besos) hasta los partidarios de cambiar estos gestos de contacto por otras manifestaciones verbales (un simple ¡hola!) y no verbales ${ }^{3}$ más distantes (sonrisa, cabezazo, etc.).

Este trabajo parte de una idea básica: una cosa es la representación de la realidad reflejada en los medios y otra muy distinta, la realidad en sí. Como señala Robles (2006: 175): "Lo que sabemos sobre nuestro entorno social y aún aquello que conocemos del mundo lo advertimos a través de los medios de comunicación”. Ahora bien, según advierte Buckingham (2005: 100), "los medios no nos ofrecen una transparente 'ventana sobre el mundo', sino más bien una versión mediada del mundo. No se limitan a presentar la realidad sino que la re-presentan".

En relación con el brote epidémico de la gripe A, como sostiene Camacho (2009), "la prensa española ha ofrecido una información demasiado alarmista y sensacionalista" y, según Lorente (2010), los medios de comunicación han proyectado "una imagen desmesurada, catastrófica y espectacular de los peligros asociados a la pandemia".

Puesto que esta investigación pretende estudiar la realidad mediática sobre el tema elegido, la fuente primordial de donde se extraen los datos es la prensa escrita y digital. Concretamente se han examinado las ediciones digitales de El País y El Mundo y la edición impresa del $A B C$ durante un periodo de seis meses, comprendidos entre el 24 de abril y el 16 de octubre de 2009. La elección de estos diarios responde a que son los de mayor tirada y difusión en nuestro país y, por tanto, los de mayor impacto sobre la población. La recogida de noticias se realizó mediante un vaciado

${ }^{2}$ Como afirman Vaqué Rafart, Gil Cuesta y Brotons Agulló (2009): "A finales de marzo de 2009 fue aislado un nuevo virus de influenza A (H1N1) de origen porcino en dos niños de California con síntomas de gripe. Dicho virus se diseminó inicialmente por México y EEUU, y después internacionalmente".

${ }^{3}$ El trabajo de Poyatos (1994) resulta básico a la hora de abordar el tema del lenguaje no verbal. 
diario de estos periódicos. Se analizaron también noticias, artículos de opinión y reportajes difundidos en estos y otros medios de comunicación después de estas fechas y otros documentos, como recomendaciones de las autoridades sanitarias ${ }^{4}$.

Para desarrollar el trabajo se han seguido básicamente dos pasos: selección de la muestra y creación del corpus; y clasificación, descripción y explicación de la información recogida.

En las páginas siguientes se recuerdan, en primer lugar, las informaciones difundidas sobre la gripe $A$, que transmitieron la idea de su elevado grado de contagio y el peligro que suponía su propagación. Se recogen después las recomendaciones de las autoridades sanitarias para evitar contraerla, que consistían básicamente en extremar las medidas de higiene, evitar el contacto físico con otros y aumentar la distancia social. Finalmente, se analizan, a partir de lo que escribieron los medios periodísticos, los efectos que estas medidas de protección sugeridas tuvieron sobre ciertos besos empleados habitualmente por la gente al desempeñar ciertas actividades y al participar en ciertas tradiciones.

\section{LA GRIPE A ESTÁ EN EL AIRE}

Desde finales de abril de 2009 la gripe A estaba en el aire. Estaba en el aire porque el aire estaba impregnado de las continuas noticias que insistían en la facilidad de su contagio e informaban de la aparición de nuevos casos en distintos países. El protagonismo de los media en esta crisis sanitaria fue tan grande que estudiosos como Jara (2009: 44) consideran que este brote de gripe A ha sido "la pandemia de los medios de comunicación” y la gripe más mediática hasta el momento.

A través de las noticias se supo que el virus de la nueva gripe —que afectaba a los bronquios, los pulmones y los alvéolos- se transmitía por diversas vías, aunque la principal era la de las secreciones respiratorias. Al parecer, estas secreciones, en forma de minúsculas gotas, conseguían desplazarse hasta alcanzar los dos metros de distancia si el portador del virus no tenía la precaución de taparse la boca al toser o estornudar. Pero había más. Se decía que la gripe A era tan contagiosa que había que tener también en cuenta los cauces de transmisión indirectos, lo que potencialmente convertía en contaminado todo cuanto rodeaba a la gente: los papeles y objetos que hubieran tocado los ya contagiados, los pasamanos de las es-

\footnotetext{
${ }^{4}$ Para la elaboración de este artículo se han tenido en cuenta, además del Informe Quiral (Revuelta y De Semir 2008), los trabajos de Camacho (2009) y de Lorente (2010).
} 
caleras, los pomos de las puertas, las barras y asientos de los transportes públicos, los mostradores de las cafeterías, los vasos, los cubiertos, etc. A esto había que añadir las propias personas que habían contraído esta gripe o eran sospechosas de tenerla, cuyo contacto se sugería evitar.

\section{LAS RECOMENDACIONES SANITARIAS: EL CONTACTO SIN TACTO}

En este escenario llegaron las recomendaciones. La gripe A llegó marcando distancias. Las autoridades sanitarias de los países afectados aconsejaron evitar el contacto físico ante el peligro de pandemia. En nuestro país, se difundieron desde los media tres mensajes fundamentales: taparse la boca y la nariz con un pañuelo desechable al estornudar o toser; lavarse las manos con agua y jabón frecuentemente; y acudir de forma responsable a los servicios de salud para que no se produjeran colapsos. En general, se sugería ser muy minuciosos en la aplicación de medidas de higiene tanto personal como doméstica - limpiando mucho y ventilando las casas-, y tomar precauciones respecto a las demás personas — porque nunca se sabía cuáles de ellas podían ser portadoras del virus-.

El Colegio de Médicos de Madrid, por su parte, puso en circulación el lema: "No beses, no des la mano, di hola", que incidía en la necesidad de suprimir por el momento algunas costumbres fuertemente arraigadas en nuestra cultura. El 8 de agosto de 2009 un teletipo de la agencia EFE (EFE 2009c) lo interpretaba así: "Los médicos proponen menos besos y más saludos a la japonesa". Y es que para los galenos el mejor método de evitar el contagio era no tocar a los demás.

Además de las propuestas reseñadas ${ }^{5}$, hubo otras que en realidad lo que hacían era proyectar estas medidas de carácter general sobre situaciones específicas y descendían a un mayor nivel de detalle. Al no besar y no tocar, se sumaron así recomendaciones como evitar lugares concurridos, trabajar desde casa (San Martín 2009), sustituir los contactos presenciales por los telefónicos y las reuniones cara a cara por videoconferencias, separar los pupitres en los colegios y eliminar el agua bendita de las iglesias (Moreno 2009).

5 Algunos periódicos consideraron "poco tranquilizadora" la actitud del gobierno. Un editorial de el diario El País del 15 de agosto de 2009 criticaba que: "Si lo que pretendía el Ministerio de Sanidad al presentar su campaña para prevenir el contagio de la gripe A era tranquilizar a la población, probablemente haya conseguido el efecto contrario. Al admitir que todo lo que puede hacer una persona para tratar de evitar la infección es tomar medidas del tipo lavarse las manos con jabón, limpiar el polvo de los muebles o evitar los besos, implícitamente se está asumiendo una gran vulnerabilidad ante la pandemia". 
Mientras tanto, y desde el momento en que se tuvo conocimiento de este tipo de gripe, las noticias iban mostrando imágenes de personas con mascarillas, que conducían a asociar la gripe A con la idea de un peligro omnipresente e ineludible y a proyectarla como una grave amenaza para la salud. Este alarmismo mediático, como diría Gil Calvo (2003), provocado por la permanente presencia de la gripe A en los medios de comunicación, generó una fuerte presión psicológica y social y causó miedo ${ }^{6}$. Esta emoción ${ }^{7}$ obligó a adoptar en muchos lugares públicos — como colegios, centros de trabajo, restaurantes y cafeterías- algunas medidas. Así, algunos centros de enseñanza enviaron circulares a los padres pidiéndoles un mayor celo en las medidas de higiene y el aislamiento de los niños con posibles síntomas de la enfermedad. En otros casos, se colocaron carteles indicando el modo de prevenir esta gripe ${ }^{8}$ e incluso, en otros, se llegó a poner dispensadores de jabón desinfectante por los pasillos. Se sugería una asepsia total.

La llegada de la gripe A, debido al bombardeo mediático que se llevó a cabo desde finales de abril, aumentó la preocupación de la gente que, ante la percepción social de peligro, incrementó su desconfianza. Esta actitud quedó reflejada en las páginas de los periódicos, que resaltaban que esta enfermedad convirtió "en centro de todas las miradas a aquellos que tosen o estornudan en lugares como el metro o el autobús" e hizo que los ciudadanos interpretaran "cualquier alergia, resfriado o dolor de cabeza de sus amigos o vecinos como una posible gripe A" (Sahuquillo 2009).

En países como España, además, la gripe A sembró desconcierto porque se lanzó la idea de que para mantenerse a salvo del virus había que cambiar el modo habitual de relacionarse con los demás. Al margen de lo que suponía en el círculo social más cercano renunciar al calor del abrazo y la camaradería, en culturas como la española determinados modos de saludar se consideran muy fríos e incluso descorteses. Ante la expansión del virus H1N1 cierta gente se planteó si hacer caso o no de las estrictas recomendaciones de las autoridades sanitarias, si conservar el saludo con beso, abrazo y/o apretón de manos o sustituirlo por otros gestos más asépticos y seguros. Decía el sociólogo Gil Calvo que "la sociedad del toqueteo" en la que vivimos no es fácil que se modifique ${ }^{9}$ y añadía que:

\footnotetext{
${ }^{6}$ Para el tema del miedo véanse los trabajos de Gil Calvo (2003) y Bauman (2007) y en relación con el miedo en las crisis sanitarias, el libro de Jara (2009).

${ }^{7}$ Para la definición de miedo véase Marina (2006: 33) quien sostiene que esta emoción equivale "a la ansiedad con causa conocida".

${ }^{8}$ En la Universitat de València, por ejemplo, se colocaron numerosos carteles de este tipo.

9 También opina así Jesús de Gándara, Jefe de Psiquiatría del Complejo Asistencial de Burgos, sociólogo, autor de El planeta de los besos y experto en besos, quien afirma
} 
Puede producirse una epidemia de alarmismo alimentada por el amarillismo de los medios o por los intereses partidistas de algunos o pueden aparecer barreras que nos hagan pensar: yo sólo voy a tocar a los míos y a los otros no (en Sahuquillo 2009).

Según se informaba a finales de agosto de 2009 en el periódico $\mathrm{La} \mathrm{Ra-}$ zón (EFE 2009d), una encuesta de Yaboo a la que respondieron más de diez mil internautas, concluía que un $64 \%$ de españoles no estaba dispuesto a dejar los besos de lado, mientras que un tercio renunciaría al estrecho contacto para evitar el contagio. Entre los partidarios de abandonar estas formas de salutación tradicionales había quien veía una parte buena en este cambio. Por ejemplo, R. Cantalapiedra (2009) en el diario El País del 9 de agosto, recoge la siguiente opinión sobre el abandono de besos y encajadas de mano: "Esto tiene su parte positiva porque despacharemos a los plastas y a los espesos de medianoche con un bola y un adiós, y si te he visto no me acuerdo. Y, además, a un metro de distancia, como poco".

Frente a los signos de saludo que se basan en el contacto físico, se aconsejó como fórmula alternativa la sonrisa. Se propuso el uso de este gesto, que expresa apertura, receptividad, alegría y comprensión, porque se ve desde lejos e indica que el camino de acercamiento está abierto. Estas son las razones por las que Hogue (2000: 151) dice que cuando se desea iniciar una conversación con alguien, no hay "nada mejor que una sonrisa. Esta manifestación no verbal reemplaza a muchas palabras y constituye un medio fácil y eficaz de entrar en contacto con la gente". Por todo esto no resulta extraño que la sonrisa fuera uno de los gestos recomendados para luchar contra el contagio de la gripe A, como quedó de manifiesto en los medios de comunicación, que hacían sugerencias del tipo: "Sustituya los besos y los apretones de manos por conductas de empatía como sonrisas o saludos" (Mateos 2009).

Otra de las alternativas que se plantearon a la hora de sustituir el ósculo fue la de lanzar besos al aire. Estos, que se oponen a los dados a través de la piel, son aéreos y se dan a distancia. En este grupo sobresale "el beso con alas", realizado mediante el gesto de besarse la mano y soplar hacia donde se encuentra la persona a quien se envía. Según Morant y Peñarroya (2004: 98) se trata de un beso sin contacto muy empleado en las despedidas a medida que se aleja la persona que se va, o en los conciertos cuando el artista quiere agradecer a la multitud asistente las muestras de afecto recibidas, o por las reinas del carnaval que los lanzan a los espectadores del desfile.

que "Los comportamientos no cambian por decreto. Ya podemos prohibir, que el mundo va a seguir, porque los labios de los amantes, de los padres, de los hijos, van al beso por tendencia natural" (EFE 2009d). 
Palomar (2009), en un artículo publicado en el diario Las Provincias el 16 de agosto de 2009, resume lo que algunos, reacios a los cambios de salutación, decidieron hacer: mantener los saludos habituales — para no quedar mal ni ofender a nadie- pero irse después corriendo y con disimulo para desinfectarse. El periodista hacía este relato:

El hijo de un amigo atrapó la gripe A y permaneció aislado varios días en un hospital. Se ha repuesto sin ningún problema [...]. Todo correcto. Sin embargo, nada causa tanta inquietud como la proximidad de ese ente amorfo, invisible y con tintes apocalípticos llamado gripe A. La razón y la ciencia opinan que no debemos perder el control y sucumbir ante ataques de histeria colectiva pero les confieso que, mientras el hijo de mi amigo yacía aburrido sobre el lecho del hospital, yo dudaba sobre si saludar a mi amigote dándole la mano como hago siempre o cambiar ese contacto carnal por un cabezazo afectuoso a tres metros de distancia por si las moscas. En un alarde de valor impropio de mi cobardía, le tendía la mano y se la estrujaba incluso con más fuerza que lo habitual mientras mascullaba: “Qué tal, cómo va tu niño?”. Aunque luego, subrepticiamente, en cuanto la ocasión aparecía, me largaba al cuarto de baño para lavarme las manos con doble dosis de jabón y frotamiento extra.

Los besos fueron, con todo, los principales causantes de la división de opiniones. De algún modo, se convirtieron en catalizadores a la hora de decidir entre seguir relacionándose como de costumbre o recurrir a otras alternativas. Parecía normal, teniendo en cuenta su intensa presencia en nuestra cultura. Otaola, escritor y abogado, destacaba el papel del beso "como símbolo":

El beso en la mejilla o en las manos se ha usado desde tiempo inmemorial como gesto de bienvenida y de despedida; el Beso de la Paz aparece expresamente en el Nuevo Testamento, besos de respeto, se dan sobre la Torah cuando ésta es introducida en la sinagoga; en los templos cristianos, cuando se lee la Biblia, se besan las reliquias; en las iglesias ortodoxas es común el beso de los iconos, así como en otros contextos se besan estatuas, o a los líderes, como signo de lealtad. Se besan los dados en el casino para pedirles suerte y es común el beso en los cuentos de hadas como fuerza curativa con capacidad para romper encantamientos como en la Bella Durmiente o también como símbolo de protección como en la leyenda del Anillo de los Nibelungos. Incluso en la masonería el beso fraternal es también un acto lleno de significado, está asociado a la paz (Otaola 2009).

Aunque recuerda que el beso tiene también su lado oscuro y que "Existe el beso de la Mafia que puede significar reconocimiento y también muerte, el beso de Judas que significa traición, el beso de Satán que significa condenación eterna" (Otaola 2009).

Para entender la polémica que se suscitó a raíz del señalamiento del beso como vehículo de contagio del virus H1N1, conviene insistir además en los beneficios del beso sobre el estado de ánimo. Besar, al margen de ser una 
forma de saludar, hace sentir bien. Esta caricia gustativa se considera básica en el bienestar de la persona, ya que aumenta la autoestima de la gente, que al recibirla o al darla se siente querida ${ }^{10}$. Esta muestra de afecto se considera asimismo una gran aliada frente a la depresión. Por eso, el lingüista Sebastià Serrano (2003: 50) afirma que "a menudo, cuando nos sentimos mal, necesitamos caricias y no pastillas”. Con la irrupción de la gripe A, los besos - tanto los que tienen lugar en el espacio privado como en el ámbito de las relaciones sociales o los vinculados a las tradiciones- pasaron a ser uno de los gestos más desaconsejados, por eso se analizará con más detenimiento cuáles fueron las reacciones ante algunos de sus usos. De entre la enorme tipología de besos (Cane 1995; Madariaga 1995; Morant y Peñarroya 2004; Arribas 2004) se tendrán en cuenta solo dos grandes grupos: los profesionales, habituales en el ejercicio de ciertas actividades, y los característicos de determinadas tradiciones y rituales.

\section{Besos profesionales}

Dentro de este apartado se analizan cinco tipos de besos: los políticos, los escolares, los deportivos, los televisivos y los navideños.

\subsection{Besos políticos}

En la cultura española los besos constituyen el modo habitual de saludo en numerosos escenarios. Entre ellos, el político. La Ministra de Sanidad, Trinidad Jiménez, no dudó en continuar ofreciendo un saludo con beso en la mejilla a sus compañeros y contrincantes políticos en plena crisis de la gripe A, a pesar de predicar lo contrario. Parecía que ella, como otros españoles y latinos, no sabía si seguir o no el rito habitual en el encuentro con otros. Algunos informadores, como Esther Esteban (2009), centraron sus artículos, a principios de septiembre de 2009, en los besos de Jiménez: “Besar no mata y los españoles somos muy besucones' afirma la ministra, con resignación cuando algún periodista le pide que predique con el ejemplo y evite posibles contagios limitando sus saludos a estrechar la mano".

En el ámbito político hubo otros besos destacables, como uno de Esperanza Aguirre y Alberto Ruiz Gallardón, que sirvió de contraejemplo en el

${ }^{10} \mathrm{El}$ inconveniente que presenta esta caricia es que puede contagiar determinadas enfermedades como la meningitis. Hubo mucha polémica en el caso del sida, hasta que se demostró que el contagio no se producía a través del beso y por eso, la campaña "No cambies tu vida por el sida" lanzada por el Ministerio de Sanidad difundió unos carteles en los que se decía: "Besarse y abrazarse NO da". 
Estado mexicano de Hidalgo en un momento en que se estaba desaconsejando este gesto de salutación (Xornal.com 2009). En las calles de la capital de este Estado se colgaron cientos de carteles dentro de la campaña para combatir el virus H1N1 en los que aparecía una fotografía de este beso entre los dos políticos con el epígrafe, "Evita saludar de beso". El 13 de noviembre de 2009 la prensa española se hacía eco de la retirada de estos anuncios que formaban parte de la campaña de salud contra la gripe A llevada a cabo en la ciudad de Pachuca.

\subsection{Besos escolares}

Algunos profesores de niños de corta edad, al incorporarse al curso académico 2009-2010, protestaron ante las propuestas de las autoridades sanitarias. La periodista Mar Ferragut (2009) relataba el caso del colegio Rei Jaume I, de Mallorca, en el que los profesores de infantil se preguntaban con preocupación si no podían abrazar a los niños cuando lloraban. "¿No puedo dar besos a mis alumnos?", decía uno de ellos, entre la incredulidad y la sorna. Y se insistía en que no se trataba tan sólo "de las lógicas muestras de afecto entre profesores y críos con las que ya se ha creado un vínculo tras varios años de clases", y que "Fomentar el contacto también forma parte de los objetivos pedagógicos".

\subsection{Besos deportivos}

La práctica de muchos deportes (las carreras ciclistas, por ejemplo) acaba normalmente con el reparto de trofeos y besos a los ganadores ${ }^{11}$. Con la gripe A los besos y abrazos deportivos amenazaron con desaparecer. Así, según una noticia publicada a comienzos de noviembre, la Asociación Sueca de Fútbol pidió que se eliminase el típico apretón de manos entre los jugadores antes y después del partido para evitar que se pudieran transmitir virus (Terra 2009). Por otra parte, en Alemania, Susanne Huggett, directora de un laboratorio de investigación, solicitó a los hinchas germanos ante el inicio de la Bundesliga de fútbol 2009-2010 que "no celebren efusivamente los goles y las victorias de sus equipos para evitar la propagación". Sus recomendaciones fueron estas: "No hay que darse la mano, ni besarse ni tampoco abrazarse al celebrar un gol". Y, dirigiéndose a los espectadores, hizo otra sugerencia: "Si tiene usted cerca alguien que estornuda y moquea constantemente, debería pensar en cambiar de sitio" (Ecodiario 2009).

\footnotetext{
${ }^{11}$ En este aspecto resulta interesante el artículo de Montero (1992: 6).
} 


\subsection{Besos televisivos}

Nada más surgir la gripe A fueron visibles ciertos cambios en los guiones de televisión. México, uno de los países más prolíficos en la producción de telenovelas, además de haber vivido la aparición de los primeros casos de esta enfermedad, parece que fue uno de los más afectados por estos cambios. Así lo relataban a finales de abril algunos medios informativos, cuando explicaban que:

Desde que estalló la alarma por la epidemia, en los estudios de Televisa dejaron de grabar escenas que contuvieran besos, tan medulares al género. Y los guionistas recibieron la indicación de buscar otras maneras de mostrar acercamiento y pasión entre los protagonistas, por ejemplo, a través de miradas y gestos (EFE 2009a).

Casi una semana después, El Mundo (EFE 2009b) recogía unas declaraciones de Nicandro Díaz, el productor de Mañana es para siempre, una de las telenovelas de mayor éxito de Televisa, afirmando que desde que estalló la alarma por la epidemia no se había grabado ninguna escena que contuviera besos. Según el mismo artículo, José Luis Estrada, encargado de prensa y relaciones públicas de la telenovela mexicana Un gancho al corazón, afirmaba que "aunque los actores no están poniendo ningún problema porque se les ha garantizado que todo está controlado, en la grabación también se están restringiendo las escenas de besos y todo el mundo va con mascarilla".

\subsection{Besos navideños}

Las personas que trabajaron durante las Navidades de 2009 interpretando el papel de Papá Noel tuvieron una misión extra en su trabajo: la de protegerse del virus de la gripe A, ya que debido a su estrecho contacto físico con numerosos niños, pasaron a considerarse como grupo de riesgo. La prensa se hizo eco de este cambio en el modo de relacionarse con los más pequeños:

[...] las autoridades sanitarias de EE.UU y las de otros países como Hungría han advertido del riesgo que corre Santa Claus y han lanzado una serie de recomendaciones específicas para él. Entre ellas, no besar a los chavales que acudan a él, aunque se lo pidan, y dejar a un lado sus tradicionales guantes blancos para poder desinfectarse más cómodamente las manos con jabón seco (que no necesita agua) (EFE 2009g).

Además de suprimir los besos, las autoridades sanitarias húngaras, con el fin de evitar nuevos contagios, difundieron un comunicado pidiendo a todos los Papás Noel del país que se vacunaran contra el virus H1N1. 


\section{Besos tradicionales}

Los besos enraizados en las tradiciones culturales también se vieron afectados como consecuencia de la gripe A. Veamos seguidamente ejemplos de lo que ocurrió en algunas de estas manifestaciones significativas, concretamente en determinados besos comerciales, legendarios y religiosos. Entre estos, unos son específicos de ciertas zonas y otros son comunes en diversos países.

\subsection{Besos comerciales}

La gripe A afectó a algunas tradiciones que tenían al beso como protagonista. Es el caso de la semana de la dulzura, que desde 1989 se festeja en Argentina del 1 al 7 de julio y que justamente vivió una crisis cuando cumplía su vigésimo aniversario. El Diario Popular de ese país, el 8 de julio de 2009, lanzaba al aire la pregunta: “¿Te animás a un beso?”, porque se veía venir que esta costumbre — "una buena oportunidad para intercambiar con amigos, familia, novio/a, amante, una golosina por un beso"- corría el peligro de no celebrarse, como consecuencia de "una grave preocupación mundial: la gripe A".

\subsection{Besos de leyenda}

Son aquellos que prometen cumplir un deseo si se dan. En Girona, por ejemplo, existe la creencia popular de que quien desee volver a esta ciudad ha de besar el Cul de la Lleona, una imagen que forma parte de una columna ubicada en la Plaça de San Feliu, y que ha dado lugar al dicho "si vas a Girona tienes que besarle el culo a la leona”. Las autoridades locales, ante la entrada de la nueva gripe A en nuestro país, retiraron, a final de agosto de 2009, la escalinata de hierro de acceso a este monumento, utilizada por los visitantes de la ciudad para seguir con la tradición que marca la leyenda. El consistorio adoptó esta medida para reducir el riesgo de contagio de la primera pandemia del siglo XXI y sugirió a los turistas sustituir el beso directo sobre la piedra por el beso a distancia (EFE 2009f).

\subsection{Besos religiosos}

Los ósculos ritualizados de la religión católica se han dejado para el final porque en ellos tienen reflejo buena parte de nuestras tradiciones. Tan abundantes son los besos sagrados como en el terreno de las relaciones 
personales. Dentro de los besos sagrados, además de los de respeto a los sacerdotes (su primera misa acaba con un besamanos), y a los distintos escalones de la jerarquía eclesiástica (al Papa, a los cardenales y a los obispos se les besa el anillo), se encuentran muchos otros. Por ejemplo, según Aldazábal (1994: 61):

En la liturgia es frecuente el lenguaje del beso. El sacerdote besa el altar al inicio y al final de la celebración. El que proclama el evangelio besa después el libro, mientras dice en secreto: "las palabras del evangelio borren nuestros pecados".

En la celebración de la misa sobresale asimismo el beso de la paz entre los fieles como expresión de concordia fraterna (Madariaga 1995: 90). Este ósculo, según la prensa, se vio afectado a raíz de la gripe A. En la Basílica de Alicante a mediados de agosto de 2009, el párroco no dudó aconsejar encarecidamente recuperar "el saludo en forma de reverencia" para darse la paz en lugar de utilizar las formas tradicionales "como el beso, abrazo o el apretón de manos" (Valdés 2009). Reacciones las hubo para todos los gustos. Un hombre comentaba a un periodista: "Como el propio cura comprenderá, no voy a dejar de darle un beso a mi mujer, ni le voy a rechazar la mano a alguien que me la ofrezca en misa". Lo mismo parecía pensar el párroco de la Encarnación de Marbella, José López, quien opinaba así por las mismas fechas: "No puedes hacer nada para que la gente no se dé la mano o dos besos para darse la paz, porque es lo mismo que hacen en la calle cuando se saludan" (Moreno 2009).

En las iglesias y santuarios son frecuentes otros tipos de ósculos sacros, como los de veneración a las imágenes. Estos besos religiosos están muy fuertemente arraigados en nuestra cultura. En este sentido, Xosé Ramón Mariño (1987: 170-171) recuerda que en el cristianismo "la costumbre de dar a besar las reliquias a los fieles es muy antigua" y que, por ejemplo, "lo específico de las romerías no es la participación en la liturgia sino el contacto directo con las imágenes y reliquias del santuario". También en los templos, en fechas señaladas, como apunta Christian (2004: 16), el sacerdote presenta cierta imagen ${ }^{12}$ o ciertos objetos sagrados para que los fieles los veneren, para que sean tocados o besados en la pierna, en el pie, en la mano, etc. De esta manera a través de este gesto de proximidad y confianza los creyentes demuestran su fe y devoción, y la creencia en que el poder de la imagen puede transmitirse a través de su contacto.

Ante la llegada de la nueva gripe, se produjo división de pareceres con respecto a esta muestra de piedad popular. Una parte de los creyentes se

${ }^{12}$ El día de Navidad o el día de los Reyes Magos después de la misa se da a besar al Niño Jesús. La gente suele besarle la rodilla. 
reafirmó en su opinión de que "La devoción necesita el beso" (M. C. G. 2009). Así se expresaba a mediados de agosto José María, un cristiano que acababa de pasar sus labios por los pies del Cristo crucificado de la basílica del Pilar.

Esta actitud generó respuestas como las siguientes, recogidas el 15 de septiembre durante la fiesta de la Santísima Virgen del Camino en su santuario de León: “¡cómo se le va a decir sólo hola a La Virgen!”, "De algo habrá que morir", “¿Cómo van a ser Cristo y la Virgen fuente de una enfermedad si se acude a ellos precisamente en busca de sanación?” (Torres 2009). En la misma celebración, el alcalde de Valverde de La Virgen, David Fernández, fue más allá negando el peligro de contagio — "la Virgen cura la gripe A"- y otra persona participante en el mismo acto hacía esta afirmación: "no creo que el manto de la Virgen sea un vehículo de transmisión de la gripe A peor que darse besos entre los políticos". Y una muestra más: el día de esta festividad las autoridades políticas, militares y eclesiásticas que acudieron al lugar dedicado a la Virgen besaron sin dudarlo su manto (Torres 2009).

Frente a quienes decidieron mantener las tradiciones religiosas a pesar de posibles contagios, hubo quienes consideraron que besar o no a las imágenes no era tan importante y se podía suprimir este acto porque, a fin de cuentas, "el culto se lleva por dentro" y "la salud es lo primero". El párroco de la Encarnación de Marbella, José López, sí que veía los tradicionales besapiés y besamanos de imágenes como potenciales focos de infección y expresaba así su opinión: "Creo que se estaría tentando a la suerte. Para venerar a una imagen no hace falta besarla" (Moreno 2009).

Hubo ejemplos de imágenes que se quedaron sin besos. Algunos toledanos evitaron besar la medalla de la Virgen del Sagrario, una tradición que se repite en la ciudad cada 15 de agosto, aunque se les dio la posibilidad de lanzarle besos desde la distancia o de tocarla con la mano y besarse esta después (EFE 2009e). La junta rectora de la Asociación de la Virgen y Mártir Santa Eulalia de Mérida optó por eliminar el besamanos de la imagen que se realiza cada 4 de octubre para evitar posibles contagios de gripe A entre los feligreses, a quienes se ofrecieron alternativas como hacer una reverencia o dar un beso a la estampa de la santa (Europa Press 2009).

Fue paradójico el caso de la Virgen de Vallivana, que liberó a Morella de una peste en el siglo XVII y que se quedó sin besos por culpa de una enfermedad del siglo xxI. En agosto de 2009, los feligreses decidieron limitarse a pasar por delante de la imagen, rezar una oración y hacer una inclinación con la cabeza (Maura 2009). Durante el mismo mes, San Antolín, en Palencia, tuvo que conformarse con la genuflexión de sus devotos (Negro 2009) y no quedó a salvo de esta ausencia de contacto el Apóstol Santiago, 
que no recibió el abrazo habitual de una parte de sus peregrinos (Cuiña 2009).

\section{CONCLUSIONES}

La gripe A, una enfermedad altamente nociva y peligrosa según los medios de comunicación, vino acompañada de unas recomendaciones por parte de las autoridades sanitarias que aconsejaban entre otras medidas el aumento de la distancia social. Estos consejos proponían cambiar las manifestaciones de salutación y afecto, concretamente los apretones de mano y besos, y sustituirlas por otras fórmulas más asépticas.

Durante los primeros meses, ante el temor mediático, quedaron afectados numerosos tipos de besos, por ejemplo, los políticos, escolares, deportivos, televisivos, comerciales, navideños, legendarios y religiosos. De todo este grupo unos desaparecieron, otros amenazaron con desaparecer y otros tantos causaron muchas dudas entre la gente. Una parte de la población se sintió internamente dividida entre continuar con su forma habitual de relacionarse con los demás o renunciar a cierto tipo de roces y aumentar las distancias.

Ahora, cuando ya ha pasado más de un año, parece haberse cumplido la predicción que en agosto de 2009 realizaron algunos comunicadores en el sentido de que la afectividad táctil se impondría a la gripe A. A pesar del bombardeo mediático sobre el virus AH1N1 y de su aparición constante en las conversaciones durante varios meses, esta pandemia no ha modificado en general una práctica cultural tan arraigada en nuestra cotidianidad como son los besos, porque estos signos expresivos de afecto y camaradería no cambian fácilmente y menos en una sociedad como la nuestra acostumbrada al roce y al contacto.

\section{BIBLIOGRAFÍA CITADA}

Aldazábal, J. 2002. Vocabulario básico de liturgia. Barcelona: Centre de Pastoral Litúrgica. Arribas, A. 2004. Bésame mucho. Breve historia del beso. Madrid: Alianza.

Bauman, Z. 2007 Miedo líquido. La sociedad contemporánea y sus temores. Barcelona: Paidós.

Buckingam, D. 2005. Educación en medios. Barcelona: Paidós.

Camacho, I. 2009. "La 'gripe A', en la prensa española". Revista Latina de Comunicación social 64: 2-17.

Cane, W. 1995. El arte de besar. Barcelona: Atalaya.

Christian, W. A. 2004. "Sobrenaturales, Humanos, Animales: Exploración de los límites en las fiestas españolas a través de las fotografías de Cristina García Rodero", en P. 
Martínez-Burgos y A. Rodríguez (coords.), La fiesta en el mundo hispánico: 13-32. Cuenca: Ediciones de la Universidad Castilla-La Mancha.

Gil Calvo, E. 2003. El miedo es el mensaje. Riesgo, incertidumbre y medios de comunicación. Madrid: Alianza.

Hogue, L. L. 2000. La comunicación. Un arte que se aprende. Santander: Editorial Sal Terrae.

Jara, M. 2009: La salud que viene. Nuevas enfermedades y marketing del miedo. Madrid: Península.

Lorente, J. I. 2010. "H1N1. Virus, discurso del riesgo y gestión mediática de la alarma sanitaria". Comunicación y desarrollo en la era digital. II Congreso Internacional de la Asociación Española de Investigadores de la Comunicación (AE-IC). Málaga. www.alic2010Omalaga.org/upload/ok/37.pdf (consultado 22-05-2010).

Madariaga, L. 1995. Historia del beso. Madrid: Libertarias/Prodhufi.

Marina, J. A. 2006. Anatomía del miedo. Barcelona: Anagrama.

Mariño, X. R. 1987. Las romerías, peregrinaciones y sus símbolos. Vigo: Edicions Xerais de Galicia.

Morant, R. y M. Peñarroya. 2004. Tres finestres obertes al món de la comunicació. El llenguatge del tacte, l'olfacte $i$ el gust. València: Editorial Denes.

Poyatos, F. 1994. La comunicación no verbal. Madrid: Istmo.

Revuelta, G. y V. De Semir. 2008. Medicina y salud en la prensa diaria. Informe Quiral 10 años. Barcelona: Observatorio de la Comunicación Científica UPF.

Robles, F. 2006. "Del espectáculo al testimonio: dos formas de presentar la realidad", en Espejismos de papel. La realidad periodistica: 173-198. México: Facultad de Ciencias Políticas y Sociales-UNAM.

Serrano, S. 2003. El regal de la comunicació. Barcelona: Ara Llibres.

Vaqué Rafart, J.; T. A. Gil Cuesta y M. Brotons Agulló. 2009. "Principales características de la pandemia por el nuevo virus influenza A(H1N1)". Medicina Clínica 133/13: 513521.

\section{Artículos periodísticos citados}

Cantalapiedra, R. "Se prohíbe besar". El País. Madrid. 9 de agosto de 2009. http:www. elpais.com/articulo/madrid/prohibe/besar/elpepiespnad/2009o809elpmad_4/Tes (consultado 20-10-2009).

Cuiña, S. "Muchos peregrinos evitan ya el abrazo al Apóstol por la Gripe A". El Correo Gallego. 16 de agosto de 2009. www.wlcorreogallego.es/santiago/ecg/muchos-peregrinos-evitan-abrazo-apostol (consultado 20-10-2009).

Diario Popular. “¿Te animás a un beso?”. 8 de julio de 2009. www.diariopopular.com.py/ ?q=node/47118/image_gallery (consultado 20-10-2009)

Ecodiario. "Piden a hinchas alemanes que no sean efusivos para evitar la gripe porcina". 8 de agosto de 2009. http://ecodiario.eleconimista.es/internacional/noticias/1459110/ 08/09/piden-a-hinchas-alemanes-que-no-sean-efusivos-para-evitar-la-gripe-porcina.html (consultado 20-10-2009).

EFE. 2009a. "Prohíben besos en las telenovelas mexicanas", www.ciudad.com.ar/2009/ 04/29/actualidad/01908228.html (consultado 20-10-2009).

EFE. 2009b. "La epidemia de gripe porcina deja a las telenovelas sin besos". elmundo.es. www.elmundo.es/elmundo/2009/05/05/television/1241525548.html (consultado 20-102009). 
EFE. 2009c. "Los médicos proponen menos besos y más saludos a la japonesa", 8 de agosto de 2009.

EFE. 2009d. "La gripe A marca distancias". La Razón. 29 de agosto de 2009. http: www.larazon.es/noticia/-la-gripe-a-marca-distancias (consultado 20-10-2009).

EFE. 2009e. "Algunos toledanos respetan a la Virgen sin besos: también respetan a la gripe", 15 de agosto de 2009. www.soitu.es/soitu/2009/08/15/info/1250350321_ 191195.html (consultado 20-10-2009).

EFE. 2009g. "Girona retira escalinata para besar el 'Cul de la Lleona'". www.abc.es/agencias $/$ noticia. asp?noticia $=965222 \&$ titular $=$ Girona + retira + escalinata + para + besar + cul $+d e+l a+$ Lleona+evitar+contagio+gripe+A (consultado 20-10-2009).

EFE. 2009h. "Papá Noel quiere vacunarse de gripe A". elmundo.es. 7 de diciembre de 2009. www.elmundo.es/elmundosalud/2009/12/07/medicina/1260194735.html (consultado 11-1-2010)

Esteban, E. "Los besos de la ministra". http:www.diariodirecto.com/opinion/esther-esteban/ 2009/09/01/esther-esteban-7144 (consultado 20-10-2009).

Europa Press. "Mérida elimina el besamanos de su patrona pero Badajoz lo mantiene". 7 de septiembre de 2009. www.elperiodicoextremadura.com (consultado 20-10-2009).

Ferragut, M. “¿No puedo dar besos a mis alumnos?”, diariomallorca.es. 1 de septiembre de 2009. www.diariodemallorca.es/mallorca/2009/09/02/dar-besos-alumnos/499462.html (consultado 20-10-2009).

M. C. G. "La devoción necesita el beso". El Periódico de Aragón. 16 de agosto de 2009. www.elperiodicodearagon.com/noticias/noticia.asp?pkid=518563 (consultado 20-102009).

Mateos, M. "Gripe A, ¿estamos a salvo en el trabajo?", El Mundo, 6 de septiembre de 2009.

Maura, J. "Sin besos para la Virgen de la Vallivana". Las Provincias. 23 de agosto de 2009. www.lasprovincias.es/valencia/20090823/comarcas/besos-para-virgen-vallivana (consultado 20-10-2009).

Montero, R. "Besos y otras cosas", El País Semanal. 22 de noviembre de 1992.

Moreno, C. "Higiene bendita". 24 de agosto de 2009. www.diariosur.es/20090824/marbella/ higiene-bendita-20090824.html. (consultado 20-10-2009).

Negro, M. "San Antolín se queda sin besos". 30 de agosto de 2009.

http://rtvcyl.es/fichaNoticia.cfm/PALENCIA/20090830/Gripe\%20A/san/antolin/ (consultado 20-10-2009).

Otaola, J. "El beso como símbolo". El Correo Digital. 5 de septiembre de 2009. www.elcorreodigital.com/vizcaya/20090905/opinion/beso-como-simbolo-20090 (consultado 20-10-2009).

Palomar, R. "Tu mentira es mi verdad". Las Provincias. 16 de agosto de 2009.

Sahuquillo, M. R. "Los besos ganarán a la gripe A". El País. Vida E Artes. 31 de agosto de 2009. http:www.elpais.com/articulo/sociedad/besos/ganaran/gripe/elpepisoc/ 20090831/ elpepisoc_1/Tes (consultado 20-10-2009).

San Martín, O. R. "Los expertos recomiendan a Zapatero consultas telefónicas contra la gripe A". El Mundo. 31 de julio de 2009.

Terra. "Las medidas más curiosas para evitar el contagio de la gripe A". 5 de noviembre de 2009. http://noticias.terra.es/Especiales/gripe-a/actualidad/curioso-h1n1-medidasvino-mono. (consultado 11-01-2010).

Torres, A. "Besos al manto de la Virgen del 'tamiflú". 16 de septiembre de 2009. www.lacronica.net/2009/09/16/leon/embesos-al-manto-de-la-virgen-del-tamiflu. (consultado 2010-2009). 
Valdés, A. "El párroco de la Basílica quiere no dar la paz con besos y abrazos para evitar la gripe A". 17 de agosto de 2009. www.diarioinformacion.com/alicante/2009/08/ 17/daos-fraternalmente-paz-tocar. (consultado 20-10-2009).

Valverde, E. "Gripe no frena besos, abrazos y apretones". 10 de octubre de 2009. www.aldia.cr/ad_ee/2009/octubre/10/nacionales2118428.html (consultado 20-10-2009).

Xornal.com. "México pone como mal ejemplo para la Gripe A el beso entre Aguirre y Gallardón". 12 de noviembre de 2009. www.xornal.com/artigo/2009/11/12/sociedad/ mexico-pone-mal-ejemplo-gripe-beso-aguirre.gallardon/2009111214123073754.html (consultado 11-01-2010).

Fecha de recepción: 2 de marzo de 2010

Fecha de aceptación: 1 de junio de 2010 